\title{
Soberania Fiscal e Globalização
}

\section{Reinaldo Chaves Rivera}

Mestrando em Direito pela UFPR e Membro do NUPESUL.

$\mathbf{A}$

s questōes tributárias envolvidas

nas relações internacionais, entre Estados independentes e entre cidadãos de Estados independentes, e nas relações entre Estados independentes componentes de blocos ou comunidades econômicas, são, hoje, objeto de grandes indagações na ordem jurídica internacional.

O tema cresce em importância no Brasil da atualidade, onde interesses do governo e dos investidores nacionais não se confinam às fronteiras do país, impondo-se que os investimentos, contratos comerciais e demais atos negociais sejam postos na esteira da globalização da economia, cujas implicações são inevitáveis diante das dissemelhanças dos tratamentos tributários de cada país ou bloco econômico.

Aliás, estas diferenças têm sede na profunda e notória mudança de perfil que vem sofrendo o comércio internacional. Como bem asseverou MARCO AURÉLIO GRECO em recente trabalho publicado na Revista Dialética de Direito Tributário,' conceitos de direito comercial de vetusta origem não guardam referencial com o mun. do moderno, lembrando o professor paulista que, hodiernamente, o exame há de ser lançado tendo-se em conta a mobilidade da renda, do consumo e dos agentes econômi$\cos$, em contraposição a conceitos clássicos como os de fronteira e de controle aduaneiro. O próprio conceito de soberania dos Estados vem sendo objeto de detidos estudos resultando em importantes proposições doutrinárias.

Sobre o tema e em face do regramento constitucional brasileiro, alinhavou BETINA TREIGER GRUPENMACHER que: "A acepção clássica de soberania deve, portanto, ser revista pois se apresenta incompativel com a integraçäo econômica pretendida pelo constituinte. Os processos de integração entre Estados impõem a releitura do conceito de soberania". ${ }^{2}$

Não diferentemente, mesmo que em outra dimensão (a nacional, interna), crescente é a importância das questões relativas ao tratamento tributário no Brasil dos fluxos econômicos que são vertidos ao nosso país, oriundos de investimentos estrangeiros, diretamente por pessoas naturais, ou por intermédio de empresas e outras estruturas negociais.

1. "Comércio Exterior e Novas Realidades - Problemas Emergentes". In Revista Dialética de Direito Tributário, nº 44, p. $116-137$.

2. Tratados internacionais em matéria tributária e ordem interna. São Paulo: Dialética, 1999, p. 34. 
Insertas na temática encontram-se duas vertentes: a primeira, sobre a renda e o capital e a pluritributaçăo internacienal; a segunda, acerca da soberania fiscal, como conceito decorrente da própria soberania do Estado.

Quanto ao imposto de renda, seja das pessoas jurídicas, seja das pessoas físicas, que fazen investimentos ou que desenvolvem atividades econômicas em Estados estrangeiros, sobrelevam as questões pertinentes ao tratamento tributário relativo a este imposto quanto aos ingressos de investimentos no Brasil, e bem assim o tratamento pelo mesmo imposto em outros países. Pródiga é a legislação brasileira neste setor jurídico, valendo lembrar, apenas como exemplos mais modernos, as disposições contidas nas Leis $n{ }^{\circ}$ 9.249/95 e 9.532/97 acerca do problema da tributação dos dividendos de origem estrangeira.

Deixando de lado o princípio da territorialidade, o Brasil adotou a tributação da chumadü "rcrida mindial" (world wideincome), com isto gerando conflitos com normas de Direito Internacional.

No escólio de ALBERTO XAVIER, as inovações legislativas brasileiras referentes à tributação da renda mundial por vezes geraram conflitos com normas de direito internacional, como vê-se nesse excerto de sua obra:

“O regime de transferência fiscal internacional, criado pela Lei $\mathrm{n}^{\circ} 9.249 /$ 95 , revelava-se também incompatível com os tratados contra a dupla tributação celebrados pelo Brasil.
$\mathrm{O}$ art. VII dos referidos tratados (que seguem a redação do art. VII da Convenção Modelo da OCDE) dispôe no seu $\mathrm{n}^{\mathrm{O}} 1$ que os lucros de uma empresa de um Estado Contratante só podem ser tributados nesse Estado, a não ser que a empresa exerça sua atividade no outro Estado Contratante por meio de um es. tabelecimento estável aí situado. Se a empresa exercer sua atividade deste modo, os seus lucros podem ser tributados no outro Estado, mas unicamente na medida em que forem imputáveis a esse estabelecimento estável." ${ }^{\text {3 }}$

\section{A legislação tributária brasileira} (onde inserem-se não só textos de leis ordinárias, mas até mesmo atos administrativos expedidos pelas autoridades fiscais competentes), é vasta e inclui toda sorte de questões relativas à tributação dita internacional e, não raro, desvendam critérios inadequados à realidade econômica globalizada. São exemplos as regras que tratam do fluxo de investimentos em empresas multinacionais, mormente no que pertine ao tratamento fiscal dos preços praticados, ou seja, a tratativa tributária do Brasil e de outros países e blocos econômicos quanto aos preços de transferência (transfer pricing) entre empresas coligadas. Inegáveis são os reflexos da economia globalizada e do aumento do comércio internacional, conforme sejam as variações tributárias daí conseqüentes. O tratamento tributário dos chamados preços de transferência pode ser fator de alteração dos rumos dos investimentos estrangeiros, e em maior grau das empresas transnacionais.

3. Direito tributánio internacional do Brasil. 5. ed., atualizada. Rio de Janeiro: Forense, 1998, p. 357. (O itálico é do original.) 
A globalização, não há de se negar, é um fenômeno com raízes nos interesses econômicos das pessoas, empresas e das próprias nações. Bem por isso as questões tributárias assumem papel relevante neste cenário. Entre elas, vale citar:

- efeitos fiscais sobre o imposto pago no estrangeiro;

- exigência de reciprocidade de tratamento fiscal;

- efeitos decorrentes dos regimes de tributação favorecida, ou da não-tributação, quando configuram-se os chamados "paraísos fiscais";

- aceitabilidade dos documentos expedidos por órgãos fiscais estrangeiros (inclusive o problema das ordens jurídicas sobrepostas acerca das formalidades exigidas para a aceitação de documentos);

- os direitos do contribuinte face à mudança de regras tributárias (de cunho formal inclusive) dos países estrangeiros.

O imposto de renda, por exemplo, pode ser utilizado como forma de atração de investimentos estrangeiros e como forma de retenção de investimentos nacionais no país. De regra, os Estados reservam-se o direito de tributar a remessa de lucros, somente deixando de fazê-lo em face dos tratados internacionais para evitar a dupla tri. butação, sob a invocação do seu poder so. berano de tributar os residentes e mesmo não residentes quando, neste caso, exista um elemento de conexão.

Emergente a globalização das rela. çōes entre países, empresas e pessoas, o tema mostra-se palpitante e de grande importân. cia na atualidade do estudo do Direito Tributário Internacional, mormente porque os interesses de arrecadação, e muitas vezes a tributação de caráter extrafiscal, geram conflitos com os interesses particulares.

Como exemplo desses interesses tencionados, colhe-se a questão da transferência de mercadorias e serviços entre empresas multinacionais coligadas, recentemente regrada pela lei brasileira, cujos preços são estabelecidos pelos órgãos fiscais.

Embora oportunizando aos contribuintes a ampla defesa, a lei brasileira inverteu o ônus da prova, pondo o contribuinte, por vezes, frente à impossibilidade de de. monstrar que o preço por ele praticado guar. da referência com o padrão internacional.

Também os investimentos estrangeiros no Brasil, a correspondente remessa de lucros, dividendos, royalties, remuneração de debêntures, juros, e outras formas de pagamento a pessoas residentes em países estrangeiros, sobretudo no casos em que não há Tíatados Intcinacionais para evitar a bitributação, têm significado específico no estudo do tema.

Num outro viés da problemática, não menos importante, está o embate entre conceitos da maior importância: de um lado, a soberania fiscal e, de outro, a igualdade material entre contribuintes e os Estados, pois é de utilidade agregar-se ao conceito de isonomia a idéia de que os contribuintes somente poderiam estar sujeitos à dupla tributação da renda quando existente um acordo ou tratado nesse sentido, e não o contrário, como entende-se e pratica-se hodiernamente, onde, na ausência dos acor- 
dos e tratados, pratica-se a dupla tributaçâo da renda livremente por dois ou mais países, aí gerando a chamada dupla tributação ou pluritributação da renda, de efeitos nocivos ao livre trânsito dos capitais e dos investimentos.

A questão se põe diante do interesse maior das pessoas, físicas e jurídicas, enquanto atores nos planos interno e internacional nestes tempos de franca globalização da economia e das relações interpessoais, daí derivando um processo de investimentos em outros países do globo, onde sîo desconsideradas as fronteiras e as culturas diferenciadas.

Esta é uma realidade do mundo moderno que ao jurista não pode passar despercebida. De outra parte, a ausência de acordos e tratados internacionais não pode ser vista como um óbice intransponível a uma prática legítima e de efeitos reconhecidamente úteis a todas as nações, muito embora presentes interesses conflitantes entre paises desenvoividos e em desenvolvimento, como o Brasil.

A soberania fiscal, portanto, deve ter seus contornos investigados, ou melhor, reinvestigados, para saber da possibilidade de mitigar o seu rígido conceito, e saber se os contribuintes, vistos no cenário globalizado, devem ser penalizados com tributações gravosias com incidências duplas ou mesmo plúrimss, o que, muitas vezes, inviabiliza o trânsito dos capitais e, pois, desfavorece os investimentos que podem trazer empregos e progresso para as sociedades envolvidas.

\section{JOÃO DÁCIO ROLIM ${ }^{4}$ anotou} que: "Não é fácil aceitar de imediato o fato consumado de que a dupla tributação internacional só pode ser evitada por acordos bilate. rais ou multilaterais celebrados entre os Estados" visão esta que deriva de uma arraigada intelecção de soberania política e jurídica, decorrente da qual os Estados podem tributar toda renda ou patrimônio que tenha alguma conexão com um determinado território. ROLIM entende que a não-tributação da renda ou do patrimônio por dois ou mais Estados é uma decorrência da "natureza das coisas e dos próprios princípios que regem o direito internacional público, o limite da soberania dos Estados e o ne bis in idem, que também informam o direito tributário internacional", 5 de forma que, na análise da questão, não deve o jurista desprecatar-se da necessária consideração ao princípio natural do ne bis in idem e do direito reconhecido mundialmente à liberdade, à livre iniciativa no campo do trabalho e à igualdade entre os povos e os indivíduos, princípios estes que não se contrapỗem à autodeterminação dos Estados.

Trata-se de uma visão moderna e que enfrenta o conceito de soberania em face das vicissitudes da economia globalizada.

Mas, parece correto afirmar, os instrumentos de negociação (acordos ou tratados para evitar a bitributação) ainda serão utilizados em larga escala como forma exclusiva para superar ou minorar a carga tributária mais onerosa decorrente da dupla ou plúrima tributação da renda ou do

4. "Da Tnbutaçāo da Renda Mundial - Principios Juridicos". Artigo publicado no Repertório IOB de Jurisprudência, n² 4/96, p. 87-85.

5. $10 \mathrm{eNm}$ 
patrimônio, sobretudo se considerado que soberania política e soberania fiscal são conceitos distintos e que podem conviver em harmonia ainda que comportando espectros distintos.

Embora os Estados acatem limitaçōes à sua soberania política no que tange à livre circulação de pessoas, capitais e bens, acabam por utilizar-se de mecanismos fiscais (invocando a soberania fiscal) para a sua autodefesa. Exemplo rutilante pode ser colhido da recente crise entre Brasil e Argentina, em que este segundo país adotou salvaguardas contra a importação de outros países, inclusive os do Mercosul. A oneração tributária nas importações, bem como os subsídios fiscais a determinados segmentos da economia são importantes instrumentos de agregação ou desagregaçẩo entres os países de um bloco econômico.

No processo de integração econômica, ensina ELIZABETH ACCIOLY:" "para se alcançar o mercado comum, devem-se galgar essas duas primeiras etapas", referindo-se às anteriores etapas da zona livre de comércio e da união aduaneira. Subjacente ao aspecto econômico está a questão tributária em todas essas fases de integração, a ponto de serem necessárias modificações na legislação dos Estados para criarem-se sistemas tributários compatíveis com os interesses comuns do bloco. Exemplo disto é o do imposto sobre a circulação de mercadorias, para o que o Brasil está preparando, no âmbito da sua reforma tributária, um imposto nos moldes adotados nos países do Mercosul, ou seja, um imposto sobre o valor agregado.

Certamente muito há para ser revisto e obtemperado pelos países integrantes do Mercosul. Animam-se, contudo, argentinos, brasileiros, paraguaios e uruguaios diante do sucesso exemplar da União Européia, onde as divergências, ao revés de fazerem perdurar os conflitos, constituíramse no grande motive para a conciliação e a consolidação do bloco econômico.

6. Mercosul \& Uniāo Européia - estrutura juridico-institucional. Curitiba: Juná, 1996, p. 20. 